\title{
Dosimetric Assessment of Routine X-Ray Examination at Selected Health Clinics in Perak Using Commercialized Optically-Stimulated Luminescence Dosimeter (OSLD)
}

\author{
M. T. Saidin ${ }^{1,2}$, A. A. Rahman ${ }^{1}$, H. H. Harun ${ }^{3,5 *}$, Y. M. Radzi ${ }^{1}$, C. Anam ${ }^{4}$, \\ Z. Kayun ${ }^{3,5}$ \\ ${ }^{I}$ School of Physics, Universiti Sains Malaysia Main Campus, 11800 Minden, Penang, Malaysia \\ ${ }^{2}$ Perak State Department, Ministry of Health Malaysia, Jalan Panglima Bukit Gantang Wahab, 30590 Ipoh, Perak, Malaysia \\ ${ }^{3}$ Department of Physics, Faculty of Science, Universiti Putra Malaysia, 43400 Serdang, Selangor, Malaysia \\ ${ }^{4}$ Department of Physics, Universitas Diponegoro, Jl. Prof. Soedarto, SH., Tembalang, Semarang 50275, Indonesia \\ ${ }^{5}$ Medical Radiation Surveillance Division, Ministry of Health Malaysia, Level 4, Blok E3, Kompleks E, Pusat Pentadbiran Kerajaan \\ Persekutuan, 62590 Wilayah Persekutuan Putrajaya, Malaysia
}

\section{ARTICLE INFO}

Article history:

Received 27 December 2020

Received in revised form 30 May 2021

Accepted 14 August 2021

Keywords:

Diagnostic reference level

Entrance surface dose

Optically-stimulated luminescence

Dosimeter

Chest X-ray

\begin{abstract}
A B S T R A C T
This study aims to compare entrance surface dose (ESD) values measured with nanoDot $\mathrm{Al}_{2} \mathrm{O}_{3}: \mathrm{C}$ optically-stimulated luminescence dosimeter (OSLD) and guidance level set under the second national dose survey which utilized old-version $\mathrm{LiF}: \mathrm{Mg}, \mathrm{Ti}$ thermoluminescence dosimeter (TLD). In this study, we conducted a dosimetric assessment for posteroanterior chest X-ray (PA-CXR) examinations performed at various community clinics in Perak, Malaysia. These clinics were selected as they were excluded from the first and second national dose survey conducted in Malaysia in 1993-1995 and 2005-2009, respectively. The ESD is obtained by mounting the OSLD on the surface of polymethyl methacrylate (PMMA) slabs. The PMMA slabs were then exposed to X-ray based on the current practice of respective clinics. The results show that the $3^{\text {rd }}$ quartile of ESDs ranged from $0.180 \mathrm{mGy}$ to $0.229 \mathrm{mGy}$ which is less than the recommended guidance level of the second national dose survey by $77 \%$. ESD measured using OSLD was found to be lower than the guidance values recommended from the second national dose survey. The finding showed a good competency of the radiographer to optimize radiological practice specifically in routine $\mathrm{X}$-ray examination.
\end{abstract}

(C) 2021 Atom Indonesia. All rights reserved

\section{INTRODUCTION}

Radiation dose exposure has been prioritized by authorities since the discovery of X-ray and radioactivity in 1895 and 1927 , respectively [1]. In 2011, the International Atomic Energy Agency (IAEA) published the Radiation Protection and Radiation Safety Standards, which states eloquently that the government shall ensure that a set of diagnostic standards for medical imaging as well as for therapeutic are established [2]. Diagnostic Reference Levels (DRL) is introduced by the International Commission of Radiation Protection and the value are based on large-scale surveys or

${ }^{*}$ Corresponding author

E-mail address: hanifhaspi@gmail.com

DOI: https://doi.org/10.17146/aij.2021.1110 reported values suitable to local circumstances [3]. The DRL for common two-dimension projection of $\mathrm{X}$-ray is based on the third quartile of the Entrance Surface Dose (ESD) value which is in unit milligray (mGy).

The ESD describes radiation dose absorbed by the skin surface of the patient as shown in Fig. 1 [4]. ESD can be obtained by measuring the passive dosimeter that is put on the main entrance of the X-ray beam that enters the patient. Conventionally, ESD was measured by using thermoluminescence dosimeter (TLD) due to its reliability and commercial availability for personal and environmental dosimetry monitoring [5]. However, the drawback of TLD is that preparation and readout are time-consuming processes that make them less practical for large-scale surveys. 
Analyses and applications have seen exponential advances in nanoscience and nanotechnology in recent years. Nanotechnology, as applied to medicine, is constantly tailored to make a major shift in diagnosis. Explanations as to why these nanoparticles (NPs) are suitable for medical purposes are based on their critical and unique characteristics, such as their mass relation surface which is considerably greater than their particles, their quantum characteristics, and their ability to absorb and transport certain compounds [6]. Optically-stimulated luminescence dosimeters (OSLDs) based on aluminium oxide $\mathrm{Al}_{2} \mathrm{O}_{3}: \mathrm{C}$, such as Landauer nanoDot, have become popular amid technological advances. It has been used rapidly in recent years for radiation assessment and offers an alternative solution for dosimetry evaluation due to its cost-effectiveness [5]. In a clinical procedure, with optical stimulation of the intensity and wavelength of the stimulation light, the advent of OSLD improves the dosimetry process. The substance also displays a good linearity of radiographic energy and a good reproducibility [7].

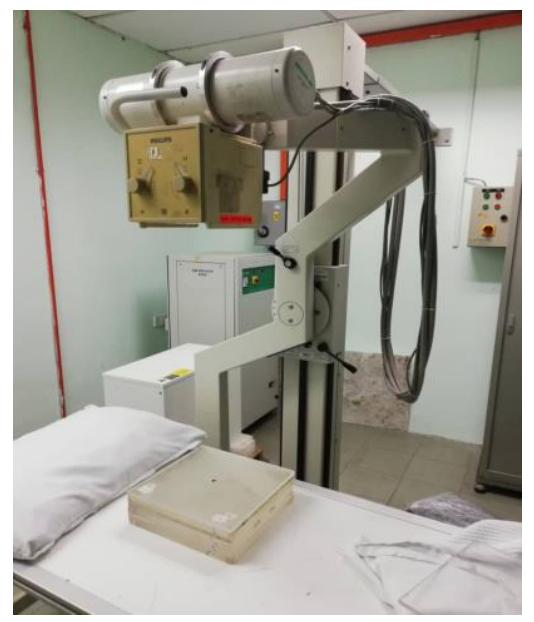

Fig. 1. General radiographic system for posteroanterior chest X-ray (PA-CXR) examination.

Previously, there are a few studies on the efficacy of OSLD in general X-ray diagnostics compared to radiotherapy studies $[8,9]$. In the diagnostic radiological processes such as computed tomography, fluoroscopy, mammography, and general radiation, OSLDs dependent on $\mathrm{Al}_{2} \mathrm{O}_{3}: \mathrm{C}$ are often defined.

Despite the rapid advancement of general $\mathrm{X}$-ray modalities with sophisticated features such as computed radiography (CR) and direct digital radiography (DDR), the dose assessment for the conventional-film radiographic system is still relevant for those institutions that rely on that scanner to produce X-ray images. Most of the health clinics in the State of Perak, Malaysia, are still using the conventional-film radiographic system to perform X-ray examination. Indeed, the exposure doses are highly dependent on the radiographic system used with a diversity of technology features [10]. Previous studies reported for conventional film radiographic systems are likely to produce higher ESD values compared to the latest radiographic system technology with spectacular dose reduction settings $[4,11]$.

The first national dose survey in Malaysia was conducted from 1993 to 1995 by the University of Malaya in collaboration with the Ministry of Health $(\mathrm{MOH})$ and the resulting data made it into the United Nations Scientific Committee on the Effects of Atomic Radiation (UNSCEAR) report [12]. Results during that time show that the ESD readings for chest X-rays examination were recorded at $0.3 \mathrm{mGy}$ [13]. Next, the second national dose survey in Malaysia was conducted from 2005 to 2009. The results have shown that the ESD value for chest $\mathrm{X}$-ray examination in Malaysia is in an upgoing trend from $0.3 \mathrm{mGy}$ [13] to $0.9 \mathrm{mGy}$ [14] which is an increase of $66.67 \%$ in 14 years. In both surveys, the ESD was still measured using TLDs attached to the patient's skin. This technique might contribute to the uncertainty of the measurement. Moreover, some of the clinical institutions, specifically in Perak, Malaysia, were not involved in both surveys due to the focus of the previous surveys on large hospitals and institutions. Thus, the dose exposure practice in those clinics is still questionable. Therefore, this study embarks on the objective to compare the ESD values measured with OSLD dosimeters to the guidance level set under the second national dose survey. It should be remembered that the national dose survey utilized the older version, LiF:Mg, Ti-based thermoluminescence dosimeter (TLD).

\section{METHODOLOGY}

This study, focusing on ESD measurement and analysis, was based on the NRPB recommendations [15]. Four health clinics in Perak had been selected as those clinics were excluded from the first and second national dose survey conducted in Malaysia.

The OSLD is a special dosimeter with a diameter of $7 \mathrm{~mm}$ and consists of plastic disks $0.3 \mathrm{~mm}$ thick placed in an illuminated plastic container of $10 \mathrm{~mm} \times 10 \mathrm{~mm} \times 2 \mathrm{~mm}$ as illustrated in Fig. 2 [16]. The readout process uses a specific InLight microStar reader (Landauer, Inc., Glenwood, IL). The signal responses of the OSLDs were precisely measured by using a Landauer Microstar reader. The reader includes a drawer that allows the 
OSLDs to be inserted into the light-tight environment of the reader. This ensures that the OSLDs are only exposed to light from the reader, and the PMT only exposed to light from the OSLD. In addition to reading these OSLDs, these Microstar readers can also be used for reading multiple types of OSLD. Depending on the type of OSLD, a unique holder adapter may be required. A rotating dial was located on the front of the reader which controls the reader operation.

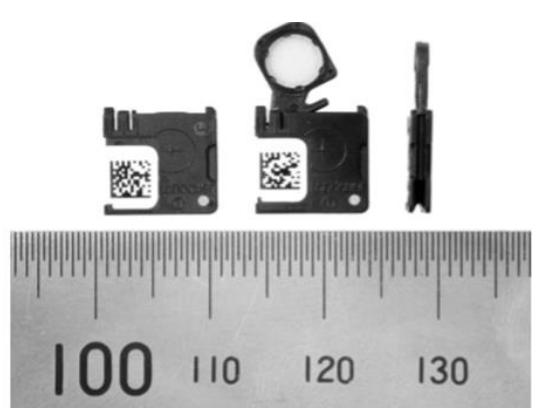

Fig. 2. InLight nanoDot OSLD from Landauer Inc. Three nanoDots, showing (left) closed, (middle) sensitive element exposed and (right) a side-on profile with sensitive element exposed.

To ensure that the OSLD is able to read the subsequent exposure, an annealing process should be carried out right after each reading. Annealing is a process to restore existing dosimeter readings to their background level so that they can be used and ready to record new readings. This method is simplified by removing the trapped electrons in the OSLDs that have been used and removing the stored energy. The bleaching method for exposure to bright white CFL bulbs was used in this research. To start the annealing process, each OSLD was opened manually by $\mathrm{Al}_{2} \mathrm{O}_{3}: \mathrm{C}$ coating and exposed to light bulbs for 8 hours. This was the minimum optimum bleaching time for the OSLD and has been implemented by our institution.

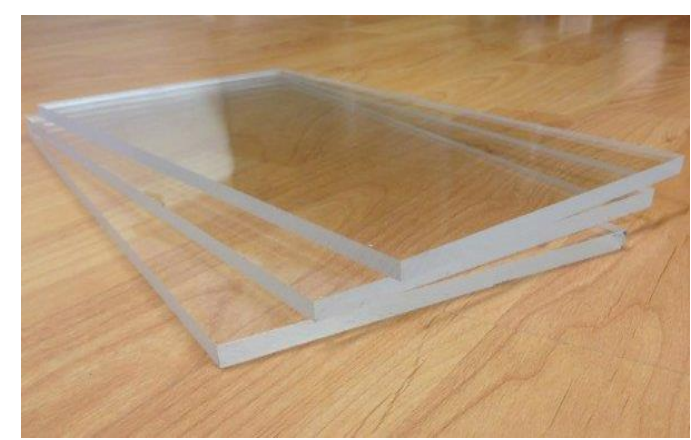

Fig. 3. Acrylic Phantom Material is clear plastic with the chemical formula $\left(\mathrm{C}_{5} \mathrm{H}_{8} \mathrm{O}_{2}\right)_{n}$, polymethylmethacrylate (PMMA).

In this study, we used acrylic glass slabs with a chemical composition of $\left(\mathrm{C}_{5} \mathrm{H}_{8} \mathrm{O}_{2}\right)_{\mathrm{n}}$, or polymethylmethacrylate (PMMA), known also as
Perspex, with a size of $180 \mathrm{~mm} \times 240 \mathrm{~mm}$ and thickness of $10 \mathrm{~mm}$ as shown in Fig. 3. Ten PMMA slabs were used to mimic the human body. The density of the PMMA phantom of $1.19 \mathrm{~g} / \mathrm{cm}^{3}$ is almost the same as water density of $0.9982 \mathrm{~g} / \mathrm{cm}^{3}$, and human tissue is made up of 60-70\% water. PMMA phantom was simulated as a surrogate of the patient based on PA (posteroanterior) chest X-ray examination from four different imaging centers in Perak, namely, Klinik Kesihatan Buntong, Klinik Kesihatan Simpang, Klinik Kesihatan Teluk Intan, and Klinik Kesihatan Pengkalan Hulu. Those four centers are denoted as $\mathrm{HC} 1, \mathrm{HC} 2, \mathrm{HC} 3$, and $\mathrm{HC} 4$, respectively. Exposure parameters were chosen as practiced by these clinics for this examination, with tube voltage ranging from 50 to $90 \mathrm{kVp}$, while tube currents were set to 5 and $16 \mathrm{mAs}$. In each examination, three OSLDs were attached on the surface of the PMMA phantom and one OSLD reserve for background measurement. The setup of the measurement is shown in Fig. 4.

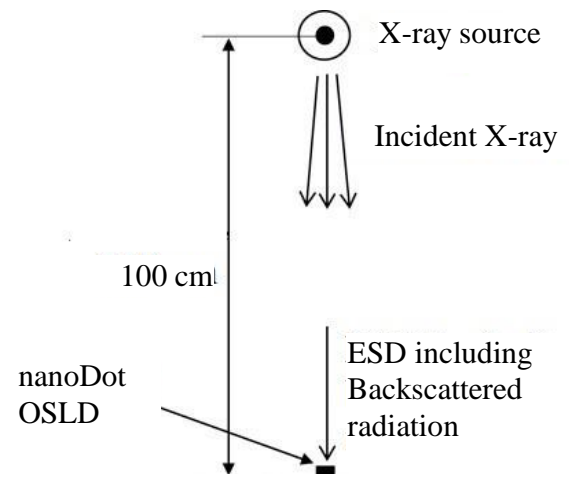

Fig. 4. The schematic diagram for direct measurement with OSL nanoDots attached to the PMMA phantom.

\section{RESULTS AND DISCUSSION}

From the measurements using OSLDs, the ESD values were calculated to be within the range $0.027-0.353 \mathrm{mGy}$ for $\mathrm{HC} 1,0.037-0.391 \mathrm{mGy}$ for $\mathrm{HC} 2, \quad 0.033-0.415 \mathrm{mGy}$ for $\mathrm{HC} 3$, and 0.029-0.313 mGy for HC4. Table 1 displays the dose parameters and mean ESD values determined with the OSLD for PA-CXR studies.

Beam energy depends on the voltage $(\mathrm{kV})$ and current (mAs) and the intensity of beam filtering exposure parameters. The energy of the radiograph varies considerably from one parameter to another. Increasing $\mathrm{kV}$ and $\mathrm{mAs}$ selection increase the amount of electron that flows to the anode, the energy of the ray transmitted to phantoms, and the penetrability of the beam [17]. When X-rays become penetrative, more energy enters the dosimeter and thus helps to expand ESD. In general, the ESD is commensurate with the tube current, 
tube voltage, and exposure time in diagnostic. Radiographers should also be made aware of the probability of reducing the patient's dose by the use of a higher $\mathrm{kV}$, lower $\mathrm{mAs}$, or shorter dosage during PA-CXR radiation examinations. It enables patients to minimize ESD without substantial loss of image quality by adjusting physical parameters and enhancing X-ray exposure techniques. To avoid potential adverse effects and eventually to reduce the chance of stochastic effects, a patient's dose must be kept as low as possible [11].

Table 1. Exposure parameters and mean ESD values measured for PA-CXR examinations using OSLD.

\begin{tabular}{ccccccc}
\hline \multirow{2}{*}{ Clinics } & \multirow{2}{*}{ mAs } & \multicolumn{5}{c}{$\begin{array}{c}\text { Mean ESD (mGy) at different } \\
\text { tube voltage (kV) }\end{array}$} \\
\cline { 2 - 7 } & & $\mathbf{5 0}$ & $\mathbf{6 0}$ & $\mathbf{7 0}$ & $\mathbf{8 0}$ & $\mathbf{9 0}$ \\
\hline $\mathrm{HC} 1$ & 5 & 0.027 & 0.042 & 0.057 & 0.078 & 0.105 \\
& 16 & 0.090 & 0.135 & 0.195 & 0.267 & 0.353 \\
$\mathrm{HC} 2$ & 5 & 0.037 & 0.059 & 0.077 & 0.105 & 0.121 \\
& 16 & 0.111 & 0.178 & 0.239 & 0.323 & 0.391 \\
$\mathrm{HC} 3$ & 5 & 0.033 & 0.060 & 0.078 & 0.109 & 0.133 \\
& 16 & 0.105 & 0.180 & 0.245 & 0.325 & 0.415 \\
$\mathrm{HC} 4$ & 5 & 0.029 & 0.042 & 0.057 & 0.081 & 0.096 \\
& 16 & 0.081 & 0.131 & 0.184 & 0.250 & 0.313 \\
\hline
\end{tabular}

There are several contributors that account for our study finding variation of ESD values among different clinics. Selected clinics had different type of scanner models with different acquisition protocols and technology levels; thus, they produced a different radiation output. This difference could be due to quantum efficiency of the system for producing an X-ray [18]. This argument suggests that scanner-dependent DRLs are needed rather than integrating all the dose report data $f$ or the development of DRLs, irrespective of the type of scanner.

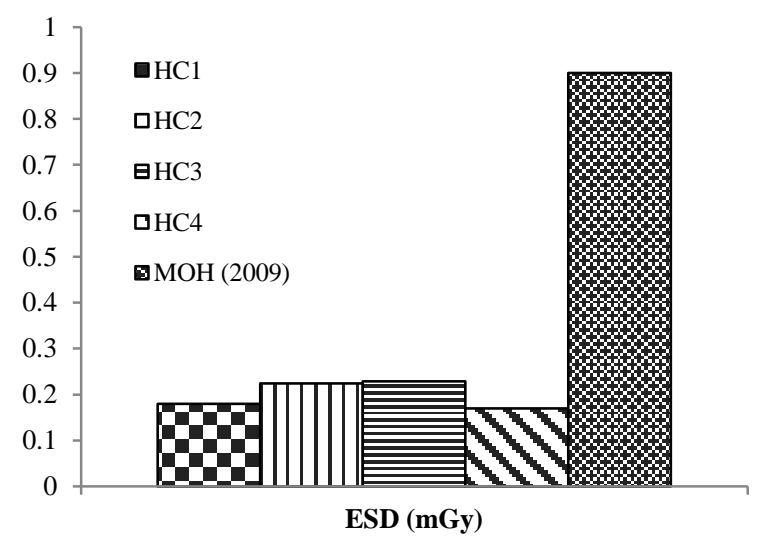

Fig. 5. Third quartile of ESD ( $m G y$ ) for PA chest X-ray examination for each clinic compared to the second national dose survey (MOH, 2009).
Figure 5 presents a comparison between the ESD obtained from OSLD and the one from the second national dose survey conducted in Malaysia (2005-2009) that used the TLD as the dosimeter. In this comparison, the ESD values demonstrated by all health clinics were below the guidance level set by the Ministry of Health Malaysia (MOH). The ESD of $\mathrm{HC} 1, \mathrm{HC} 2, \mathrm{HC} 3$, and $\mathrm{HC} 4$ were lower than that of $\mathrm{MOH}$ by a factor of 5.0, 4.0, 3.9, and 5.29, respectively.

Many factors may contribute to the ESD finding as the ESD values were remarkably lower than the results of the previous National Dose Survey. This also shows that ESD variations in $\mathrm{X}$-ray modalities can be related to the parameters of exposure. Such ESD changes may be due to the various technological features and technical parameters of X-ray equipment [19]. The large measured ESD difference of $77 \%$ between this study and $\mathrm{MOH}$ results is most likely due to the use of the older version of general radiographic system in the $\mathrm{MOH}$ study. The variance in measurements can also be attributed to different filtering mechanisms that contribute to the HVL values for each machine. Permanent filtering of the X-ray tube must be capable of reducing beam penetration by $50 \%$ [20]. Sufficient X-ray beam filtering enabled eliminating low-energy radiation which is unnecessary and degrading the image quality. As the first and second National Dose Survey in Malaysia were done a long time ago, most of the general radiographic systems used had lower-end specifications that contribute to these findings [14].

Dosimetry comparisons using OSLD for this analysis showed variance readings with the national dose survey using TLD. OSLD is better for signal reading compared to TLD as OSLD is better for diagnostic imaging using low-energy X-rays. It is also better for high-energy X-ray such as the ones used in radiotherapy [5]. OSLD also demonstrated strong accuracy and persistence in reading. Another studied OSLD was found to exhibit strong reproducibility and linearity compared to ion chamber and TLD in the general radiographic energy domain [2]. In addition, the non-destructive function, easy readout and annealing process of such OSLD provided additional advantages that are prospective for dose measurements in general radiography [5].

Generally, the ESDs from all health clinics in this research were lower as compared to the national DRL and IAEA BSS, which suggested the dose optimization and appropriateness of the OSLD for ESD assessment. This also shows that variations of ESD can be associated with the exposure parameters in X-ray machines. The different technology and 
technological parameters of an X-ray system may be responsible for such modifications of ESD [21,22]. The measurement variation may also be due to the application for each machine with various filtering and HVL thicknesses. The continuous filtering of the X-ray tube should be able to reduce the penetration of the beam by $50 \%$. Adequate $\mathrm{X}$-ray beam filtering allowed low-energy radiation to be avoided [23].

Table 2. Comparison of filtration thickness measured for HVL calculation based established standard from MS 838.

\begin{tabular}{|c|c|c|c|c|c|c|}
\hline \multirow{2}{*}{$\begin{array}{c}\text { Healt } \\
\text { h } \\
\text { clinic } \\
\text { s }\end{array}$} & \multicolumn{5}{|c|}{$\begin{array}{l}\text { HVL measurement at different tube } \\
\text { voltage }(\mathrm{mm} \mathrm{Al})\end{array}$} & \multirow{2}{*}{$\begin{array}{c}\text { MS } 838 \\
\text { Standard }\end{array}$} \\
\hline & $50 \mathrm{kV}$ & $60 \mathrm{kV}$ & $70 \mathrm{kV}$ & $80 \mathrm{kV}$ & $90 \mathrm{kV}$ & \\
\hline $\mathrm{HC} 1$ & $\begin{array}{c}2.10 \\
\pm \\
0.04\end{array}$ & $\begin{array}{c}2.62 \\
\pm \\
0.03\end{array}$ & $\begin{array}{c}3.22 \\
\pm \\
0.02\end{array}$ & $\begin{array}{c}3.63 \\
\pm \\
0.05\end{array}$ & $\begin{array}{c}4.15 \\
\pm \\
0.02\end{array}$ & \multirow{4}{*}{$\begin{array}{l}\text { Shall not be } \\
\text { less than } 2.0 \\
\mathrm{~mm} \text { Al } \\
\text { equivalent } \\
\text { for machine } \\
\text { operated in } \\
\text { the range } 70 \\
\mathrm{kV}-100 \mathrm{kV}\end{array}$} \\
\hline $\mathrm{HC} 2$ & $\begin{array}{c}2.04 \\
\pm \\
0.03\end{array}$ & $\begin{array}{c}2.51 \\
\pm \\
0.12\end{array}$ & $\begin{array}{c}2.84 \\
\pm \\
0.08\end{array}$ & $\begin{array}{c}3.43 \\
\pm \\
0.05\end{array}$ & $\begin{array}{c}3.93 \\
\pm \\
0.08\end{array}$ & \\
\hline HC3 & $\begin{array}{c}2.24 \\
\pm \\
0.08\end{array}$ & $\begin{array}{c}2.71 \\
\pm \\
0.03\end{array}$ & $\begin{array}{c}3.12 \\
\pm \\
0.02\end{array}$ & $\begin{array}{c}3.61 \\
\pm \\
0.12\end{array}$ & $\begin{array}{c}4.06 \\
\pm \\
0.08\end{array}$ & \\
\hline $\mathrm{HC} 4$ & $\begin{array}{c}2.04 \\
\pm \\
0.11\end{array}$ & $\begin{array}{c}2.62 \\
\pm \\
0.08\end{array}$ & $\begin{array}{c}3.17 \\
\pm \\
0.09\end{array}$ & $\begin{array}{c}3.64 \\
\pm \\
0.05\end{array}$ & $\begin{array}{c}4.08 \\
\pm \\
0.03\end{array}$ & \\
\hline
\end{tabular}

Table 2 compares the filtering measured for each machine during the last performance test in the four health clinics using the established standard from Malaysian Standard (MS 838). Beam filtering showed an appropriate quality of X-ray exposure for all clinics has been examined [23]. The radiation intensity is one of the essential properties in radiography that can be reduced by filtering [20]. Low energy X-rays are preferentially absorbed through filtering so without this the low energy $\mathrm{X}$-rays are likely absorbed by the patient thus contributing to a noisy image formation [24]. Generally, additional filtering from the minimum value can reduce dose. However, excessive increase of filtering is susceptible to affect image quality and leads to a higher dose as greater mAs will be required to compensate radiation intensity.

There were several limitations to this study. This study covered only PA X-ray examinations. Further investigation should expand the scope to other general radiographic examination such as abdomen/KUB (kidneys-ureter-bladder), lower and upper extremities, and lumbo-sacral AP (anteroposterior) and LAT (lateral) examinations for a more comprehensive dose assessment study. Besides, this study may further detail with different phantom type and sizes to represent different tissue attenuation and patient sizes. Lastly, since the HVLs found were only measured for the same tube current, the expansion to other general radiographic examinations could render additional information of both values as the variation tube current settings will be tested.

\section{CONCLUSION}

The results obtained have shown that the ESD measured using OSLD was found to be within the guidance values recommended from the second national dose survey by the Ministry of Health Malaysia. Assessment of ESD can be used as a reference level in particular to improve the quality of Health Clinic diagnostic services. This served as a study using OSLD to determine dose assessment for patients undergoing PA-CXR examination at the Selected Perak Health Clinic, Special consideration has to be given to adequate training for all radiographers to update patient's dose consideration and implementation of a regular performance test audit to optimize radiological practice.

\section{ACKNOWLEDGMENT}

We would like to express our gratitude to the Director-General of Health Malaysia for his permission to publish this article. We sincerely appreciate the Director and Deputy Director (Public Health) of Perak State Health Department, Medical Physicist of Perak State Health Department, and health clinics radiographers for providing us with access to the general X-ray machine and associated facilities. The first author would like to thank the Ministry of Health, Malaysia, for the scholarship given under Hadiah Latihan Persekutuan (HLP). The author also likes to thank the Ministry of Higher Education in funding of Fundamentals Research Grant Scheme (FRGS) - 6711597) to support this project.

\section{AUTHOR CONTRIBUTION}

Tarmizi and Hanif carried out the research, wrote the article, and revised it. Azhar conceptualized the central research idea and provided the theoretical framework. Yasmin designed the research and supervised research progress. Choirul Anam and Zunaide anchored 
the review and revisions and approved the article submission.

\section{REFERENCES}

1. W. R. Hendee, E. R. Ritenour and K. R. Hoffmann, Med. Phys. 30 (2003) 730.

2. Anonymous, Radiation Protection and Safety of Radiation Sources, GSR Part 3, International Atomic Energy Agency, IAEA (2014).

3. M. M. Rehani, Br. J. Radiol. 88 (2015) 11.

4. Y. Musa, S. Hashim and M. Khalis Abdul Karim, J. Phys. Conf. Ser. 1248 (2019) 1.

5. M. F. M. Yusof, M. H. Yahya, M. S. Rosnan et al., AIP Conf. Proc. 1799 (2017) 040007-1.

6. D. Z. Tan, S. F. Zhou, Y. Shimotsuma et al., Opt. Mater. Express 4 (2014) 213.

7. Y. Musa, S. Hashim, S. K. Ghoshal et al., Radiat. Phys. Chem. 147 (2018) 1.

8. C. S. Lim, S. B. Lee and G. H. Jin, Appl. Radiat. Isot. 69 (2011) 1486.

9. M. Vijayam, J.B. Shigwan, B.S. Dixit et al., Japan Heal. Phys. Soc. 1 (2000) 8.

10. E. Vañó, D. L. Miller, C. J. Martin et al., Ann. ICRP 46 (2017) 1.

11. I. R. Ajayi and A. Akinwumiju, Radiat. Prot. Dosim. 87 (2000) 217.

12. Anonymous, Sources and Effects of Ionizing Radiation Vol. I, UNSCEAR, New York (2010) 23.
13. K. Ng, P. Rassiah, H. Wang et al., Br. J. Radiol. 71 (1998) 654.

14. Anonymous, Medical Radiation Exposure Study in Malaysia, Ministry of Health Malaysia (2013).

15. Anonymous, National Protocol for Dose Measurements in Diagnostic Radiology, National Radiological Protection Board, Oxon (1992) 46.

16. L. Dunn, J. Lye, J. Kenny et al., Radiat. Meas. 51-52 (2013) 31.

17. E. Samei and D. J. Peck, Hendee's, Phys. Med. Imaging, Fifth Ed. (2019) 89.

18. F. R. Verdun, D. Racine, J. G. Ott et al., Physica Med. 31 (2015) 823.

19. R. Tanabe and F. Araki, Physica Med. 77 (2020) 48.

20. F. M. Braun, T. R. C. Johnson, W. H. Sommer et al., Eur. Radiol. 25 (2015) 1598.

21. Y. Asada, K. Ono, Y. Kondo et al., Radiat. Prot. Dosim. 187 (2019) 338.

22. W. Muhogora and M. M. Rehani, J. Med. Imaging 4 (2017) 031202.

23. Anonymous, Guidelines to Obtain Class C Licence Under the Atomic Energy Licensing Act 1984 (Act 304), The Ministry of Health Malaysia (1995).

24. I. Shirazu, C. Schandorf, Y. B. Mensah et al., Int. J. Sci. Eng. 3 (2017) 671. 